OPEN ACCESS

Edited by:

Pei Du,

Xi'an Jiaotong University, China

Reviewed by:

Hongfang $L u$,

Southeast University, China

Xinping Xiao,

Wuhan University of Technology,

China

Rana Muhammad Adnan Ikram, Hohai University, China

*Correspondence:

Lifeng Wu

wlf6666@126.com

Specialty section:

This article was submitted to

Environmental Economics and

Management,

a section of the journal

Frontiers in Environmental Science

Received: 12 August 2021

Accepted: 12 October 2021

Published: 12 November 2021

Citation:

Wang W, Chen $Y$, Xie $Y$ and Wu L (2021) Research on Influence Factors of Air Quality in the Host Area of the 24th Winter Olympic Games Based on

Grey Relational Analysis.

Front. Environ. Sci. 9:757533.

doi: 10.3389/fenvs.2021.757533

\section{Research on Influence Factors of Air Quality in the Host Area of the 24th Winter Olympic Games Based on Grey Relational Analysis}

\author{
Wei Wang ${ }^{1}$, Yan Chen ${ }^{1}$, Yuhan $X i^{1}$ and Lifeng $W u^{1,2 *}$ \\ ${ }^{1}$ College of Management Engineering and Business, Hebei University of Engineering, Handan, China, ${ }^{2}$ Hebei Key Laboratory of \\ Intelligent Water Conservancy, Hebei University of Engineering, Handan, China
}

In recent years, the continuous development of the economy and science and technology of China has caused a certain degree of pollution to the atmospheric environment on which the people depend. The current air pollution problem is actively a concern by the government and all walks of life. Based on the 2015-2019 air quality indicators and some socioeconomic indicators, this paper uses the grey correlation analysis method to analyze the Beijing and Zhangjiakou cities that will host the Winter Olympics in 2022. The study found that the three factors most closely related to the Beijing Air Quality Index (AQI) are the permanent population (0.831), energy consumption (0.801), the number of motor vehicles (0.79), and the permanent population (0.916) and industrial added value (0.905). The total output value of agriculture, forestry, and animal husbandry and fishery (0.89) are the three factors most closely related to the air quality index (AQI) of Zhangjiakou City, and the permanent population is the common factor affecting the two cities. Considering that the factors that affect the air quality of the two cities are not exactly the same, this paper combines the development positioning of the two cities and their own characteristics, and puts forward specific suggestions and opinions on the different problems faced by the two cities. The aim is to promote the continuous improvement of air quality in the two cities to reach an excellent level through scientific and feasible air management programs before the opening of the 2022 Winter Olympic Games, and help the 2022 Winter Olympics to be held smoothly.

Keywords: air quality, grey relational analysis, permanent population, governance measures, 24th Winter Olympic Games

\section{INTRODUCTION}

In recent years, China's economy, production, industry, and other aspects have been on rapid development. The requirements of the people for material life and the pursuit of spiritual life are constantly improving. Therefore, air quality has become one of the most concerning ecological and environmental issues of the public. Due to industrial development and the continuous improvement of living standards, pressure on the ecological environment has also increased. For example, industrial exhaust, automobile exhaust, coal combustion exhaust, and many other harmful gases are emitted into the atmosphere, resulting in many areas in the north of China being repeatedly covered by haze. Haze is a particular concern in the Beijing-Tianjin-Hebei region, where the air 
pollution problem is most prominent. Because the indicators for measuring air quality are affected by a variety of environmental factors, and the main air pollutants vary from region to region, analyzing the pollutants affecting air quality from multiple perspectives and selecting reasonable and valuable indicator data for correlation comparison has become the focus of research and drawn the attention of many scholars in China and internationally. Since the theory of the grey system was proposed by Professor Julong Deng in 1982, it has caused many scholars to study deeply and explore actively, making it possible to expand the depth and breadth of the grey system theory in continuous development to better serve national and social development. The advantage of the grey system theory is that it can perform a systematic analysis of the uncertainty of data with a small sample and sparse information and reveal the connections between, and potential value of, the data. Grey relational analysis, as an important branch of the grey system theory, is a new approach to factor analysis (Xiao, 1997). Grey relational analysis has now been applied to many research fields such as factor analysis, comprehensive evaluation, and program decision making (Deng, 1989). Wang et al. studied the sources and characteristics of PM2.5 in the areas where the Olympic Games were held and found that the main factors of PM2.5 pollution in the two areas were quite different, and the contribution of the surrounding areas to PM2.5 in the areas where the Olympic Games were held was nearly twice that of the remote areas (Wang et al., 2021). Liu et al. used a combination of hybrid simulation and risk analysis to study 243 cities and towns in Zhangiiakou City and found that 34 cities and towns may be affected by aviation hazards, but the construction site for the 2022 Winter Olympics will not be threatened by the acute air pollution in Zhangjiakou City (Liu et al., 2018). Zhan et al. studied the correlation between air pollutant indicators and economic and social indicators in the Guangdong-Hong Kong-Macao Greater Bay Area from 2006 to 2016 (Zhan et al., 2018). Wang and He studied the correlation between $\mathrm{PM}_{2.5}\left(\mathrm{PM}_{2.5}\right.$ is particulate matter with a diameter $\leq 2.5 \mu \mathrm{m}$ ) and six elements of air quality in Urumqi from 2014 to 2016 using grey relational analysis and found that $\mathrm{CO}$ concentration values had the greatest influence on $\mathrm{PM}_{2.5}$ (Wang and He, 2018). Based on the grey model, Ni took Wuhan City as an example and found that the main factors influencing air quality were the proportion of secondary industry, total urban population, industrial $\mathrm{SO}_{2}$ emissions, and public green space per capita $(\mathrm{Ni}, 2013)$. Gao and $\mathrm{Wu}$ used the entropy-weighted grey relation method to study the factors influencing air quality in Beijing and found that the proportion of secondary industry, average temperature, and industrial $\mathrm{SO}_{2}$ emissions were the main factors affecting air quality in Beijing (Gao and $\mathrm{Wu}, 2017$ ). Li et al. analyzed the influence factors of air quality indexes in the Beijing, Tianjin, and Hebei regions from 2013 to 2017 and showed that rainfall, wind speed, and air temperature were negatively correlated with air quality index, while relative humidity and air pressure varied from region to region (Li and Wang, 2019). Wang and Tian used grey relational analysis to investigate the influence factors of air quality in Yichang City and found that different air quality indexes had different influence factors (Wang and Tian, 2019).
Nan and Sun used a grey correlation model to analyze the correlation between $\mathrm{O}_{3}$ concentration and influencing index factors in Shanxi Province in 2015 and analyzed the factors that were more correlated with $\mathrm{O}_{3}$ from different perspectives (Nan and Sun, 2017). Wang et al. used grey relational analysis to study the factors influencing air quality in Handan from 2014 to 2018 and found that the industrial value added, energy consumption, and motor vehicle ownership were the main factors influencing air pollution in Handan (Wang et al., 2019). Wang used a modified grey relational analysis to analyze the factors influencing haze in Zhengzhou City and found that vehicle emissions, smoke and dust emissions, and construction site dust were the main controllable influence factors (Wang, 2020). Zhang et al. showed that local air pollutant emissions, lagged $\mathrm{PM}_{2.5}$ concentrations, wind speed, and $\mathrm{PM}_{2.5}$ concentrations in nearby areas had significant effects on $\mathrm{PM}_{2.5}$ concentrations in the Beijing-Tianjin-Hebei region (Zhang et al., 2018). Li et al. established an air quality research model using a particulate matter source analysis technique and concluded that the main sources of $\mathrm{PM}_{2.5}$ in Beijing were both residential and industrial (Li et al., 2015). In their 2016 study, Yan et al. showed that $\mathrm{PM}_{2.5}$ concentrations in 13 cities, including Beijing, Tianjin, and Hebei, were influenced by seasonality, and the seasons with high to low concentrations were winter, autumn, spring, and summer in order (Yan et al., 2018). Tian et al. showed that seasonal effects, land use, vehicle density, and emission intensity were the main influence factors that continued to affect air quality in Beijing (Tian et al., 2019). Chen et al. analyzed and discussed the spatial-temporal coupling relationship and restrictive factors among different cities in Ningxia Hui Autonomous Region by combining grey relational analysis with coupling coordination model and linear regression (Chen et al., 2021). Khuman et al. regarded the absolute grey correlation degree as a part of the novel R-fuzzy grey analysis framework (RfGAf). The framework based on subjective uncertainty has the advantages of capturing information comprehensively, timely, and with a wide range of adaptations (Khuman et al., 2019). Feng and Sun used the grey correlation analysis method to select important indicators for the economic, environmental, and social benefits of the environmental investment of China, and established a comprehensive evaluation model for the benefits of environmental investment (Feng and Sun, 2020). Wu et al. used a model combining grey correlation and entropy to analyze the relationship between water resources and the economy in the Beijing-Tianjin-Hebei region of China and found that the correlation between the two systems from 2015 to 2024 is weak (Wu et al., 2021). Xiao et al. combined the grey model with the coupling model to systematically study the coordination relationship between the two important factors of the economy and technology of China (Xiao et al., 2021). Zhu et al. studied the relationship between the regression coefficients and physical properties of coarse aggregates by means of grey relational analysis (Zhu et al., 2021). Fiaz et al. used the grey relational analysis method to study the first wave of COVID-19 epidemic data obtained from the worldometer website, and the research results can bring a lot of useful information to the health 
systems of many countries (Qazi et al., 2021). Li and Ye chose the grey correlation analysis method to analyze the coordination of environmental policies in the 281 prefecture-level cities in China from 2007 to 2016 and found that policy coordination has a significant positive impact on haze governance (Li and Ye, 2020). $\mathrm{Wu}$ and $\mathrm{Qu}$ proposed a new type of grey relational model of dynamic weighting function that enables the problem of multifactor and multi-attribute classification to be better solved ( $\mathrm{Wu}$ and $\mathrm{Qu}, 2020$ ). Xiao et al. proposed a grey correlation model based on language binary matrix to quantitatively evaluate the operation quality of regional industrial industries, and promoted the innovation and application prospect of the grey correlation model (Xiao et al., 2020). Wang et al. used the grey correlation method to sort the multiple stages of different alternatives in water pollution control to get the overall ranking, and then allocated resources according to priority (Wang et al., 2020). Gong et al. found that the main factors affecting the durability of mixed modified asphalt mixtures are aggregate gradation and aging temperature through the grey correlation analysis method (Gong et al., 2021). Luo et al. used the grey correlation analysis method to analyze the three aspects of energy, economy, and environment in Guangxi and Zhejiang in China, and found that energy consumption can promote economic development but inhibit environmental improvement (Luo et al., 2019).

As can be seen from the above studies, most of the studies on air quality are mainly based on meteorology, greenery, seasons, and energy consumption, while relatively few studies analyze air quality in conjunction with economic and social factors in the study region. Based on this, this paper uses grey relational analysis to study the main socioeconomic factors affecting air quality in Beijing and Zhangiakou from 2015 to 2019, finds the key influence factors through comparative analysis, and proposes specific management measures to contribute to the successful holding of the 2022 Winter Olympic and Paralympic Winter Games.

\section{DATA AND METHODS}

\section{Data Source and Processing}

In the rapid economic development of modern China, air pollution is influenced by multiple factors. Agriculture, industry, energy consumed in winter for residential heating, and many pollutants such as carbon monoxide, carbon dioxide, nitrogen oxides, and hydrocarbons emitted from motor vehicle exhaust can cause serious air pollution. The air pollution in most regions is mainly influenced by the population base, ecological environment, industrial status, and energy consumption of the region. As a super-populous city and the economic center of northern China, many factors affect the air quality in Beijing. In Zhangjiakou, the secondary and tertiary industries are developing rapidly under the 13th Five-Year Plan, and the number of domestic and foreign tourists visiting Zhangjiakou is increasing year by year. As a result, the air pollution indicators in Beijing and Zhangjiakou are affected by many socioeconomic factors. Considering the availability, reference, and outstanding representativeness of data indicators, seven air pollution-related indicators were selected
TABLE 1 | Air pollution data of Beijing

\begin{tabular}{lccccc}
\hline Indicator & $\mathbf{2 0 1 5}$ & $\mathbf{2 0 1 6}$ & $\mathbf{2 0 1 7}$ & $\mathbf{2 0 1 8}$ & $\mathbf{2 0 1 9}$ \\
\hline$A Q I$ & 7.4 & 6.8 & 5.87 & 5.35 & 4.7 \\
$P M_{2.5}\left(\mu \mathrm{g} / \mathrm{m}^{3}\right)$ & 80.6 & 73 & 58 & 51 & 42 \\
$\mathrm{PM}_{10}\left(\mu \mathrm{g} / \mathrm{m}^{3}\right)$ & 102 & 92 & 84 & 78 & 68 \\
$\mathrm{SO}_{2}\left(\mu \mathrm{g} / \mathrm{m}^{3}\right)$ & 14 & 10 & 8 & 6 & 4 \\
$\mathrm{NO}_{2}\left(\mu \mathrm{g} / \mathrm{m}^{3}\right)$ & 50 & 48 & 46 & 42 & 37 \\
$\mathrm{CO}-95_{\text {per }}\left(\mathrm{mg} / \mathrm{m}^{3}\right)$ & 3.6 & 3.2 & 2.1 & 1.7 & 1.4 \\
$\mathrm{O}_{3}-8 \mathrm{~h}-90_{\text {per }}\left(\mu \mathrm{g} / \mathrm{m}^{3}\right)$ & 202.6 & 199 & 193 & 192 & 191 \\
\hline
\end{tabular}

as a reference sequence, and 10 representative socioeconomic indicators were selected as a comparison sequence for grey relational analysis in Beijing, while six air pollution-related indicators were selected as a reference sequence and eight representative socioeconomic indicators were selected as a comparison sequence in Zhangjiakou. The air pollution data of Beijing were obtained from http://sthjj.beijing.gov.cn/. The socioeconomic data of Beijing were obtained from http://tjj. beijing.gov.cn/. The air pollution data of Zhangjiakou were obtained from http://hb.zjk.gov.cn/. The socioeconomic data of Zhangjiakou were obtained from http://tjj.zjk.gov.cn/. The air pollution data of Beijing for 2015-2019 are shown in Table 1, and the socioeconomic data of Beijing are shown in Table 2. The 2015-2019 air pollution data of Zhangjiakou are shown in Table 3, and the socioeconomic data of Zhangjiakou are shown in Table 4.

\section{Methods}

Since the air quality situation is closely related to the time point, in order to conduct a more effective analysis, this paper selected the data of air pollution and socioeconomic indicators from 2015 to 2019. However, as the sample size was relatively small, and the relationships between the data were not easily found directly, many existing statistical models were not suitable for conducting data analysis and research using such data. For example, the Pearson correlation coefficient proposed around the 1880s mainly studies the degree of correlation between two variables, but it becomes quite difficult to study the degree of correlation between multiple variables at the same time. Moreover, Pearson correlation coefficient method can only reflect the linear relationship between two variables, and the direction of correlation has some limitations. In 1982, The grey model proposed by the Chinese scholar Professor Deng Julong has been committed to solving the problem of uncertainty in terms of small samples and poor information. Among them, the grey correlation analysis model can process and mine the potential correlations between multiple indicators at the same time, and then obtain the correlation degree between multiple comparison indicators, which is a great theoretical and practical significance. In the approximately 40 years since the appearance of the grey correlation model, due to its good correlation analysis performance, it has been popularized and applied by many scholars in wide fields. Because other factors such as demographic factors, economic factors, industrial factors, and ecological factors can cause different degrees of air pollution, these complex factors can be understood as a grey system. Therefore, for this paper, it was appropriate to choose grey relational analysis for the research and 
TABLE 2 | Socioeconomic data of Beijing.

\begin{tabular}{|c|c|c|c|c|c|}
\hline Indicator & 2015 & 2016 & 2017 & 2018 & 2019 \\
\hline Resident population (10,000 people) & $2,170.5$ & $2,172.9$ & $2,170.7$ & $2,154.2$ & $2,153.6$ \\
\hline Number of tourists $(10,000$ people) & 27,279 & $28,531.5$ & $29,746.2$ & $31,093.6$ & $32,209.9$ \\
\hline Total output value (hundred million yuan) & $24,779.1$ & $27,041.2$ & 29,883 & 33,106 & $35,371.3$ \\
\hline Construction industry output value (hundred million yuan) & $1,002.6$ & $1,074.5$ & $1,210.9$ & $1,387.8$ & $1,513.7$ \\
\hline Industrial value added (hundred million yuan) & $3,458.9$ & $3,635.5$ & $3,885.9$ & $4,139.9$ & $4,241.1$ \\
\hline Output value of tertiary industry (hundred million yuan) & $20,218.9$ & $22,245.7$ & $24,711.7$ & $27,508.1$ & $29,542.5$ \\
\hline Energy consumption (10 thousand tons) & $6,802.8$ & $6,916.7$ & $7,088.3$ & $7,269.8$ & $7,360.3$ \\
\hline Private car ownership (10 thousand) & 440.3 & 452.8 & 467.2 & 479 & 497.4 \\
\hline Artificial forestation area (hectares) & 8,252 & 12,667 & 11,853 & 17,974 & 18,698 \\
\hline Park area (hectares) & 29,503 & 30,069 & 31,019 & 32,619 & 35,157 \\
\hline
\end{tabular}

TABLE 3 | Air pollution data of Zhangjiakou.

\begin{tabular}{|c|c|c|c|c|c|}
\hline Indicator & 2015 & 2016 & 2017 & 2018 & 2019 \\
\hline$A Q /$ & 4.64 & 4.5 & 4.18 & 4.11 & 3.53 \\
\hline$P M_{2.5}\left(\mu \mathrm{g} / \mathrm{m}^{3}\right)$ & 34 & 32 & 31 & 29 & 25 \\
\hline$P M_{10}\left(\mu g / m^{3}\right)$ & 78 & 83 & 70 & 69 & 56 \\
\hline $\mathrm{SO}_{2}\left(\mu \mathrm{g} / \mathrm{m}^{3}\right)$ & 31 & 20 & 16 & 14 & 11 \\
\hline $\mathrm{NO}_{2}\left(\mu \mathrm{g} / \mathrm{m}^{3}\right)$ & 26 & 27 & 25 & 23 & 22 \\
\hline $\mathrm{CO}-95_{\text {per }}\left(\mathrm{mg} / \mathrm{m}^{3}\right)$ & 1.6 & 1.4 & 1.3 & 1.4 & 1.1 \\
\hline
\end{tabular}

$\rho=0.5$. It is further confirmed that the correlation result obtained when the value of a is relatively better, in the Grey relational analysis between socio-economic factors and air pollution in Beijing and Zhangjiakou section of this paper, the value of a in the interval of $0-1$ is selected for three equal points to verify the case again.

Step 4: Calculate the grey relation using Eq. 3:

$$
\gamma_{i}\left(y_{(0)}, y_{(i)}\right)=\frac{1}{n} \sum_{k=1}^{n} \gamma\left(x_{(0)}(k), x_{(i)}(k)\right)
$$

TABLE 4 | Socioeconomic data of Zhangjiakou City.

\section{Indicator}

Resident population (10,000 people)

Number of tourists $(10,000$ people)

Total output value (hundred million yuan)

Industrial added value (hundred million yuan)

Output value of tertiary industry (hundred million yuan)

Total output value of agriculture, forestry, animal husbandry, and fishery (hundred million yuan)

Artificial forestation area (hectares)

Urban green area (hectares)

\begin{tabular}{ccccc}
$\mathbf{2 0 1 5}$ & $\mathbf{2 0 1 6}$ & $\mathbf{2 0 1 7}$ & $\mathbf{2 0 1 8}$ & $\mathbf{2 0 1 9}$ \\
\hline 442.17 & 442.51 & 443.3 & 443.4 & 442.33 \\
3,848 & $5,193.77$ & $6,259.8$ & $7,354.8$ & $8,605.06$ \\
$1,363.54$ & $1,461.05$ & $1,555.6$ & $1,536.6$ & $1,551.06$ \\
404.7 & 373.9 & 372.5 & 423.9 & 456.96 \\
574.13 & 651.86 & 726 & 791.6 & 861.87 \\
430.93 & 465.05 & 493.4 & 403.7 & 438.51 \\
47,444 & 81,075 & 137,211 & 127,392 & 50,533 \\
3,791 & 4,163 & $3,848.7$ & $3,989.7$ & $4,081.22$
\end{tabular}

analysis of the air pollution data of Beijing and Zhangiiakou, and the socio-economic indicators of the two regions. Grey relational analysis is used to determine the degree of relation between different data by the proximity of reference data and comparison data, and the specific steps of grey relational analysis are as follows.

Step 1: $Y_{0}=\left(y_{0}(1), y_{0}(2), \cdots, y_{0}(n)\right)$ as the reference sequence, and $Y_{1}=\left(y_{1}(1), y_{1}(2), \cdots, y_{1}(n)\right), \ldots, \quad Y_{m}=$ $\left(y_{m}(1), y_{m}(2), \cdots, y_{m}(n)\right)$ as the comparison sequence.

Step 2: Normalize data as in Eq. 1:

$$
X_{i}(j)=\frac{y_{i}(j)}{y_{i}(1)}, i=0,1,2, \cdots m ; j=1,2, \cdots n
$$

Step 3: Calculate the grey correlation coefficient using Eq. 2:

$$
\begin{gathered}
\xi_{i}\left(x_{0}(k), x_{i}(k)\right) \\
=\frac{\min _{i} \min _{k}\left|X_{0}(k)-X_{i}(k)\right|+\rho \max _{i} \max _{k}\left|X_{0}(k)-X_{i}(k)\right|}{\left|X_{0}(k)-X_{i}(k)\right|+\rho \max _{i} \max _{k}\left|X_{0}(k)-X_{i}(k)\right|}
\end{gathered}
$$

where $\rho \in[0,1]$ is the differentiation coefficient. According to most of the literature on the use of the grey relation coefficient, where $\gamma_{i}\left(y_{(0)}, y_{(i)}\right)$ is the grey relation of $Y_{0}$ and $Y_{i}$. If the grey relation is closer to 1 , it means that the reference sequence $Y_{i}$ has more influence on the main sequence $Y_{0}$. Otherwise, it means that the influence is less.

Step 5:

$$
\bar{\gamma}=\frac{1}{m} \sum_{i=1}^{m} \gamma_{i}\left(y_{(0)}, y_{(i)}\right)
$$

$\bar{\gamma}$ is the mean value of grey correlation obtained by all control indicators corresponding to the same reference indicator.

\section{GREY RELATIONAL ANALYSIS BETWEEN SOCIOECONOMIC FACTORS AND AIR POLLUTION IN BEIJING AND ZHANGJIAKOU}

Taking the grey relation between the air quality index (AQI) and the selected socioeconomic pollution sources of Beijing as an 
TABLE 5 | Relational analysis between socio-economic factors and air pollutants in Beijing.

Socio-economic factor

Resident population (10,000 people)

Number of tourists (10,000 people)

Total output value (hundred million yuan)

Construction industry output value (hundred million yuan)

Industrial value added (hundred million yuan)

Output value of tertiary industry (hundred million yuan)

Energy consumption (10 thousand tons)

Private car ownership (10 thousand)

Artificial forestation area (hectares)

Park area (hectares)

\section{AQI}

0.831

0.772

0.713

0.708

0.757

0.706

0.801

0.79

0.564

0.785
$\mathrm{PM}_{2.5}$

$0.803 \quad 0.84$

0.753

0.702

0.697

0.74

0.696

0.779

0.768

0.565

0.765

$\mathbf{P M}_{\mathbf{1 0}}$
0.84
0.777
0.716
0.71
0.762
0.709
0.809
0.796
0.564
0.791

$\begin{array}{cccc}\mathbf{S O}_{\mathbf{2}} & \mathbf{N O}_{\mathbf{2}} & \mathbf{C O}-\mathbf{9 5}_{\text {per }} & \mathbf{O}_{\mathbf{3}}-\mathbf{8 h}-\mathbf{9 0}_{\text {per }} \\ 0.739 & 0.888 & 0.768 & 0.954 \\ 0.702 & 0.814 & 0.727 & 0.85 \\ 0.664 & 0.743 & 0.684 & 0.758 \\ 0.66 & 0.736 & 0.68 & 0.749 \\ 0.693 & 0.795 & 0.716 & 0.825 \\ 0.659 & 0.734 & 0.678 & 0.747 \\ 0.721 & 0.851 & 0.748 & 0.901 \\ 0.714 & 0.836 & 0.739 & 0.88 \\ 0.555 & 0.573 & 0.561 & 0.561 \\ 0.711 & 0.83 & 0.736 & 0.87\end{array}$

TABLE 6 | Relational analysis between socioeconomic factors and air pollutants in Zhangjiakou.

\begin{tabular}{|c|c|c|c|c|c|c|}
\hline Socio-economic factor & AQI & $\mathrm{PM}_{2.5}$ & $\mathbf{P M}_{10}$ & $\mathrm{SO}_{2}$ & $\mathrm{NO}_{2}$ & CO $-95_{\text {per }}$ \\
\hline Resident population (10,000 people) & 0.916 & 0.903 & 0.904 & 0.762 & 0.935 & 0.879 \\
\hline Number of tourists ( 10,000 people) & 0.64 & 0.634 & 0.649 & 0.596 & 0.649 & 0.63 \\
\hline Total output value (hundred million yuan) & 0.849 & 0.838 & 0.861 & 0.726 & 0.876 & 0.821 \\
\hline Industrial added value (hundred million yuan) & 0.905 & 0.905 & 0.884 & 0.765 & 0.896 & 0.884 \\
\hline Output value of tertiary industry (hundred million yuan) & 0.766 & 0.758 & 0.779 & 0.678 & 0.785 & 0.746 \\
\hline Total output value of agriculture, forestry, animal husbandry and fishery (hundred million yuan) & 0.89 & 0.877 & 0.901 & 0.748 & 0.92 & 0.859 \\
\hline Artificial forestation area (hectares) & 0.606 & 0.6 & 0.608 & 0.567 & 0.618 & 0.597 \\
\hline Urban green area (hectares) & 0.88 & 0.869 & 0.891 & 0.743 & 0.91 & 0.848 \\
\hline
\end{tabular}

example, the following steps of grey relational analysis were carried out in calculation: the reference sequence is $Y_{0}=(7.4,6.8,5.87,5.35,4.7)$, and the comparison sequence is:

$$
\begin{aligned}
Y_{1} & =(2170.5,2172.9,2170.7,2154.2,2153.6), \\
Y_{2} & =(27279,28531.5,29746.2,31093.6,32209.9), \\
Y_{3} & =(24779.1,27041.2,29883,33106,35371.3), \\
Y_{4} & =(1002.6,1074.5,1210.9,1387.8,1513.7), \\
Y_{5} & =(3458.9,3635.5,3885.9,4139.9,4241.1), \\
Y_{6} & =(20218.9,22245.7,24711.7,27508.1,29542.5), \\
Y_{7} & =(6802.8,6916.7,7088.3,7269.8,7360.3), \\
Y_{8} & =(440.3,452.8,467.2,479,497.4), \\
Y_{9} & =(8252,12667,11853,17974,18698), \\
Y_{10} & =(29503,30069,31019,32619,35157) .
\end{aligned}
$$

From steps 1-4,

$$
\begin{gathered}
\gamma\left(Y_{(0)}, Y_{(1)}\right)=0.831, \gamma\left(Y_{(0)}, Y_{(2)}\right)=0.772 \\
\gamma\left(Y_{(0)}, Y_{(3)}\right)=0.713, \gamma\left(Y_{(0)}, Y_{(4)}\right)=0.708 \\
\gamma\left(Y_{(0)}, Y_{(5)}\right)=0.757, \gamma\left(Y_{(0)}, Y_{(6)}\right)=0.706 \\
\gamma\left(Y_{(0)}, Y_{(7)}\right)=0.801, \gamma\left(Y_{(0)}, Y_{(8)}\right)=0.79 \\
\gamma\left(Y_{(0)}, Y_{(9)}\right)=0.564, \gamma\left(Y_{(0)}, Y_{(10)}\right)=0.785
\end{gathered}
$$

were obtained.

The grey relation of each reference sequence and its corresponding comparison sequence for Beijing and Zhangjiakou were calculated using the same steps with the results shown in Tables 5 and $\mathbf{6}$, respectively.

In order to further confirm the feasibility of the resolution coefficient of 0.5 , this paper selected the resolution coefficient of $0.25,0.5$, and 0.75

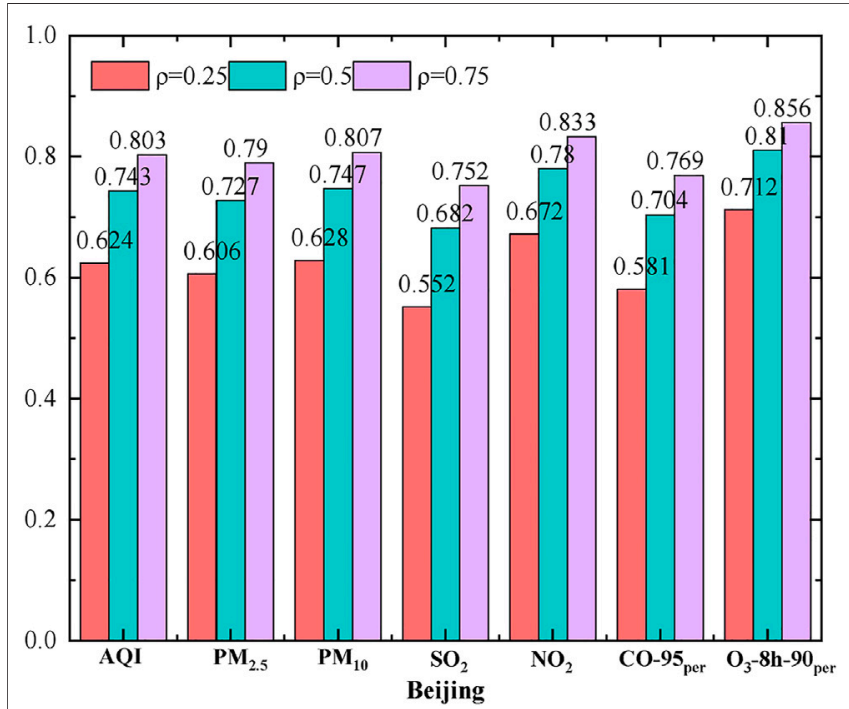

FIGURE 1 | Grey average correlation coefficient of air index under different resolution coefficients in Beijing.

for comparison. The results of the analysis of the socioeconomic factors and air pollutants in Beijing are shown in Table 5. When the resolution coefficient is 0.5 , it can be obtained from step 5 .

$$
\begin{gathered}
\bar{\gamma}_{A Q I}=0.743, \bar{\gamma}_{P M_{2.5}}=0.727, \bar{\gamma}_{P M_{10}}=0.747, \bar{\gamma}_{\mathrm{SO}_{2}}=0.682, \\
\bar{\gamma}_{\mathrm{NO}_{2}}=0.78, \bar{\gamma}_{\mathrm{CO}-95_{\text {per }}}=0.704, \bar{\gamma}_{\mathrm{O}_{3}-8 h-90_{\text {per }}}=0.81
\end{gathered}
$$

In the same way, the results when the resolution coefficients are 0.25 and 0.75 can also be calculated in steps 


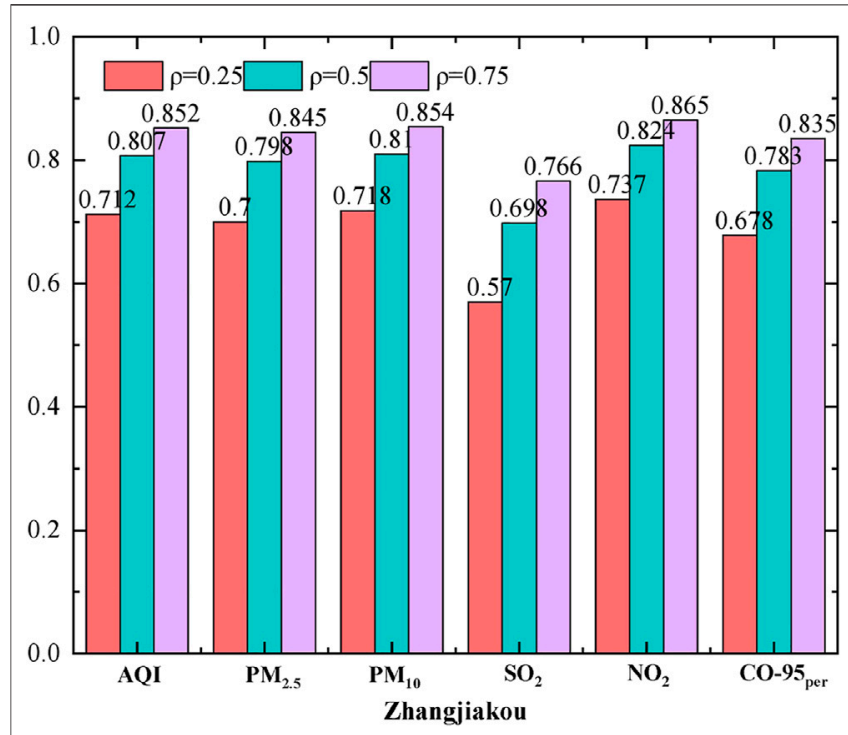

FIGURE 2 | Grey average correlation coefficient of air index under different resolution coefficients in Zhangjiakou.

1-5. The comparison of different resolution coefficient values in Beijing is shown in Figure 1, and the comparison of different resolution coefficient values in Zhangjiakou City is shown in Figure 2. From Figures $\mathbf{1}$ and 2, it can be clearly observed that when the resolution coefficient is 0.5 , it is more reasonable and objective than when the value is 0.25 or 0.75 .

\section{DISCUSSION AND RESULTS}

From the results in Table 5, it can be obtained that the three social and economic factors that are most relevant to the Beijing air quality index (AQI) are permanent population (0.831), energy consumption (0.801), and private car ownership (0.79). At the same time, these three socioeconomic indicators are also the main factors affecting $\mathrm{PM}_{2.5}, \mathrm{PM}_{10}, \mathrm{SO}_{2}, \mathrm{NO}_{2}, \mathrm{CO}-95_{\text {per }}$, and O3-8h90 per. As the capital of China, Beijing is a mega city with a resident population of more than 20 million, and the urban resident population has reached more than 10 million. Faced with such a large population, just taking essential breathing every day will produce a lot of carbon dioxide emissions. What is more, the work and daily life of these permanent residents in Beijing will cause more exhaust gas to be discharged into the natural environment to affect the air condition. Besides, the overall situation of air quality will also be affected by the large concentration of the population in some urban areas and the population of many other provinces going to Beijing for job hunting and entrepreneurship. In addition to the permanent population factor, energy consumption is the second indicator that is closely related to all air quality indicators in Beijing. Although many high-emission and high-polluting factories and facilities have been moved out of Beijing in recent years, massive emissions of air pollutants in Beijing have been solved in a short period of time. However, because the government encourages the expansion and development of the tertiary industry, it has also promoted the accelerated development of machinery manufacturing, artificial intelligence technology industries, various processing companies, and social servicerelated industries. This makes the consumption of nonrenewable energy and electric energy show a certain upward trend. Since the consumption of non-renewable resources will have a greater impact on the environment than the consumption of renewable resources, it is necessary to always strive to explore possible renewable and clean energy. On the other hand, due to the influence of the region, Beijing needs to provide a large area of heating guarantee every winter, and the consumption of energy such as coal and natural gas also increases. Many indicators that consider environmental quality are disturbed by the dual effects of weather factors and pollutant emissions in winter. Second, affected by the continuous improvement of the living standards of the current people, the private car ownership in Beijing has shown a trend of steadily increasing year by year within the time frame of the study. The increase in private car ownership will undoubtedly increase the consumption of oil, natural gas, and electric energy, resulting in the exhaust gas of vehicles using such energy as petroleum containing harmful substances such as CO, hydrocarbons, nitrogen oxides, and particulate matter of different sizes. In turn, it will have an extremely bad impact on the atmospheric environment. The research and development and vigorous promotion and use of pollution-free or low-polluting vehicles will play an indispensable role in improving the quality of the air environment in Beijing and even the whole of China.

The correlation between air pollutants and economic indicators in Zhangjiakou City is shown in Table 6. The relevant factors affecting the air indicators in Zhangjiakou City are different from those in Beijing. From Table 6, it can be seen that the most closely related to the air quality index (AQI) are the permanent population (0.916), the industrial added value (0.905), and the total output value of agriculture, forestry, and animal husbandry and fishery (0.89). These three factors are also the main factors affecting $\mathrm{PM}_{2.5}, \mathrm{SO}_{2}$, and $\mathrm{CO}-95_{\text {per }}$. For the two air indicators $\mathrm{PM}_{10}$ and $\mathrm{NO}_{2}$, the three most relevant factors are permanent population, total output value of agriculture, forestry, animal husbandry and fishery, and urban green area. To a certain extent, it shows that the urban green area plays a vital role in air purification in Zhangjiakou. From the perspective of population size, the number of permanent residents in Zhangjiakou is much less than that in Beijing. The Zhangjiakou area is affected by its geographical location, which has led to a relatively slow opening to the outside world. The overall quality of the population and other aspects of weak environmental protection awareness still need to be improved. For a long time, the rural residents in many counties of Zhangjiakou have used wood or straw to carry out their daily lives. The smoke produced by combustion contains air pollutants, such as hydrocarbons, and it will have a negative impact on the atmospheric environment. In recent years, Zhangjiakou City has worked hard to expand and open up, attracting many industrial enterprises to set up factories in Zhangjiakou to promote the economic development of the region and expand the popularity of the region. However, 
industrial enterprises need to emit a large amount of waste gas into the atmosphere to increase industrial output. The emitted fine particles, $\mathrm{SO}_{2}, \mathrm{CO}$, and other pollutants will undoubtedly have a serious impact on the local excellent atmospheric environment. It is worth further discussing how the Zhangjiakou government should change its development focus and how industrial enterprises should reduce harmful substances in exhaust gas. The natural geographical location makes the development of agriculture, forestry, and animal husbandry and fishery an important support for the economy of Zhangjiakou, and agriculture, forestry, and animal husbandry and fishery need to emit a lot of carbon oxide and nitrogen hydride in the daily production or breeding process. Therefore, it is necessary to explore a circular sustainable agriculture, forestry, and animal husbandry and fishery development model that can reduce the emission of air pollutants to a large extent. The area of urban green space can be used as a criterion for evaluating the environmental quality of a city. From the results in Table 6, it can be seen that the urban green area of Zhangjiakou City has a high degree of correlation with $\mathrm{PM}_{10}$ and $\mathrm{NO}_{2}$, indicating that the urban green area can have a greater impact on some air pollution indicators. The urban green area of Zhangjiakou City can have a greater positive effect on the absorption and decomposition of particles with larger diameters and nitrogen oxides. The government and social workers in Zhangjiakou also need to increase their energy investment and financial support in the green development of the city, and create a beautiful business card for Zhangjiakou by taking the good opportunity of taking the 2022 Winter Olympics express train.

\section{SUGGESTIONS}

\section{Suggestions for Improving Air Quality in Beijing}

1) A reasonable adjustment of the urban population layout and the reduction of the urban population density. Beijing is a mega city with a relatively high population density, and its population is the primary factor affecting its air quality. For its part, the government should consider setting up high-tech industrial parks and economic zones in Miyun District and Huairou District in order to ease the population pressure within Beijing, which could promote industrial development while also reducing the population density in central Beijing. The government should guide some Beijing administrative departments to move to Xiong'an New Area in batches, effectively dispersing local Beijing residents and other people coming to Beijing to do business in dense areas, giving full play to the complementary advantages of Beijing-Tianjin-Hebei integration. The government should increase the number of quality schools in the development zones of Beijing to reduce the population density of the schools in the city, and increase the construction of parks, shopping plazas, and fitness equipment around the city to attract people to live in good environmental conditions. In addition, the government should give certain preferential policies to workers and job seekers in Beijing to encourage them to move to Xiong'an New Area, which is the centralized bearer of the non-capital functions of Beijing, in order to further relieve the existing population pressure in Beijing.

2) Continuously optimize the energy structure and encourage the use of clean energy. The state and government should continue to promote clean energy, such as natural gas, as the main source of energy for daily life. In the industrial industry, the government should adopt certain policies to help enterprises gradually replace high pollution and high energy consumption equipment with low pollution and low energy consumption equipment; upgrade sewage equipment; strengthen energy consumption monitoring; recycle water, coal, and industrial raw materials as many times as possible; and take better optimization measures to further improve the efficiency of energy use. Air conditioners and refrigerators are most frequently used in summer. Encouraging the public to buy or switch to fluoride-free air conditioners and refrigerators will not only reduce energy consumption but also reduce the damage to the ozone. Regarding urban residential heating in the winter, the government should strive to popularize natural gas heating, electric heating, geothermal heating, and other clean heating methods as soon as possible. Where possible, streetlights in urban areas should be converted to solar power to reduce the energy consumption of public resources, while wind power stations can be set up in the northwestern part of Beijing as appropriate. The promotion of various clean energy sources will reduce the harmful emissions from the burning of nonrenewable resources, which will better promote the lowcarbon green development of Beijing and enter the 2022 Beijing Winter Olympic and Paralympic Games with improved environmental quality.

3) Promote green travel for all people and the use of new energy vehicles. The government should actively promote the public taking the subway and bus as much as possible when they go out, which is convenient and environmentally friendly. People who do need to purchase a car should be encouraged to respond to the national call for low carbon and environmental protection by purchasing hybrid or electric cars to meet their daily needs. The promotion of low-carbon travel should be increased on bus billboards and publicity boards in various public places. For new purchases and car exchanges, according to personal circumstances, the recommendation is to purchase electric or hybrid cars for daily city trips and gasoline dual-purpose cars for frequent long-distance business trips. In terms of traffic control, a limiting number system should be applied to fuel cars to reduce traffic flow, while the restrictions on new energy vehicles should be relaxed to motivate people to buy new energy vehicles. The number of refueling stations in the city should be increased along with the number of charging posts in city parking lots to ensure that new energy vehicles can be recharged in time for continuous use. The bus routes in Beijing should be optimized to make it easier for people to travel by avoiding congestion in the morning and evening rush hour bus lanes. The government should call on the 
people of the city to create a favorable travel environment for the main venue of the 2022 Beijing Winter Olympic and Paralympic Games, and to fully demonstrate the low-carbon awareness of the people of China to the rest of the world at the Winter Olympics.

\section{Suggestions for Improving Air Quality in Zhangjiakou}

1) Actively guide urban and rural residents to enhance their awareness of air protection. In order to maintain the air quality in Zhangjiakou in the long term, it is necessary to further increase the awareness of the people to air protection. This can be done by holding a series of public meetings such as "Environmental protection tips" and "Hazards of air pollution" in neighborhood committees and village committees, calling on the general public to learn more about the importance of air for human survival. Township residents should be encouraged to promote the use of natural gas, solar energy, and other environmentally friendly energy sources instead of the traditional straw burning in order to reduce emissions. Television, radio, the internet, and other information dissemination channels should be used to promote the importance of protecting the air environment. Real and rewarding methods, such as reporting, will attract people to supervise each other, and eventually everyone will consciously restrain themselves. Taking these steps will create a good social atmosphere for the hosting of the Winter Olympics and fully highlight the high-quality selfcultivation level of the Chinese people.

2) Accelerate the optimization and upgrading of industrial industries and attract high-quality enterprises to set up factories. In the industrial industry, the government should continue to deepen structural reform on the supply side, provide increased assistance to industrial enterprises to accelerate the optimization and upgrading of industrial structures, and subsidize a certain percentage of the high-energy consumption and high-pollution equipment after elimination and replacement to encourage enterprises to reduce energy consumption and reduce the emission of harmful air pollutants. Zhangjiakou should also make great efforts to attract investment, focusing on attracting low-pollution processing enterprises such as processing manufacturing and the garment industry to set up factories in Zhangjiakou. This would not only promote the development of the economy of Zhangjiakou but also help to protect the air quality in Zhangjiakou to improve continuously so as to contribute to the smooth operation of the 2022 Winter Olympic Games and Winter Paralympic Games in Zhangjiakou.

3) Ensure stable production in agriculture, forestry, animal husbandry, and fisheries, and strengthen technical guidance and research in the exploration of recyclable models. In agriculture, farmers should be encouraged to use low pollution fertilizers. Drones should be used to spray pesticides instead of traditional manual spraying. Notices should be posted in prominent locations in rural streets to clearly prohibit straw burning. More trees should be planted on some unutilized hills, which would increase the forest cover and have a purifying effect on the air environment. The livestock industry should encourage technical experts to increase the number of field guidance trips in the countryside and actively help herders to carry out scientific breeding and improve the utilization rate of farmland and feed. Animal manure should be stored centrally and regularly transported to septic tanks for treatment. Farmers near grasslands should take full advantage of their location to build horseriding facilities, both to improve their income and reduce the amount of breeding. Construct a comprehensive industrial experimental zone integrating agriculture, forestry, and animal husbandry, give full play to the advantages of agriculture, and provide organic feed. The forestry industry stabilizes the soil and protects it from wind, absorbing exhaust gas, and replenishing sufficient oxygen at the same time. For animal husbandry, in order to reduce the use of chemical fertilizers, a variety of natural fertilizers can be explored to reduce exhaust gas emissions. Efforts should be made to explore a realistic model of multiresource recyclable use. While these efforts will help ensure the stability of the daily life and livelihoods of the people, they will also help carry out the important initiative of "accelerating the reform of the ecological civilization system and building a beautiful China" emphasized by General Secretary Xi Jinping in the report of the 19th Party Congress and welcome the 2022 Winter Olympics and Winter Paralympics with a strong ecological outlook.

\section{Research Limitations and Prospects Research limitations}

With the continuous acceleration of the social process, the influence of economic factors on the atmospheric environment has become more and more guiding. However, the current economic system is difficult to sort out in the short term due to the many elements involved. Therefore, this study selects as many air and socioeconomic indicators as possible instead of selecting all the indicators as the research object is one of the limitations of this paper. In addition, this paper does not carry out joint research on the air index and social economic index of the area around the two cities.

\section{Prospects}

Since the concept of regional coordinated development is valued by the government and society, it is also of great significance to combine the grey correlation analysis model with the new coupling coordination model to study some specific regions. This paper only discusses the relationship between air pollution indicators and social economy from the perspective of time, and it is also interesting to consider combining time and space for analysis in the future. Considering that the grey relational analysis model has unique advantages in factor analysis, it can also be widely used in more fields to give play to the practical value of the model. 


\section{DATA AVAILABILITY STATEMENT}

The original contributions presented in the study are included in the article/Supplementary Material, Further inquiries can be directed to the corresponding author.

\section{AUTHOR CONTRIBUTIONS}

WW: Conceptualization, Methodology, Software, Visualization, Writing - original draft. YC: Data curation, Investigation, Survey design, Writing - review and editing. YX: Conceptualization, Survey design, Survey translation. LW: Writing - review and editing.

\section{REFERENCES}

Chen, H., Liu, L., Fang, J., Li, C., Wang, L., Quan, Q., et al. (2021). Spatio-Temporal Analysis of the Coupling Relationship Between Urbanization and EcoEnvironment in Backward Regions of China. Environ. Sci. Pollut. Res. 28 (45), 1-18. doi:10.1007/S11356-021-16240-Z

Deng, J. (1989). Grey System Theory. Wuhan: Huazhong University of Science and Technology Press.

Feng, Q., and Sun, T. (2020). Comprehensive Evaluation of Benefits From Environmental Investment: Take China as an Example. Environ. Sci. Pollut. Res. 27 (8), 15292-15304. doi:10.1007/s11356-020-08033-7

Gao, M., and Wu, X. (2017). Analysis of Influencing Factors of Air Quality in Beijing Based on Entropy Weight Grey Correlation Method. Ecol. Economy. 33 (3), 142-147.

Gong, M., Zhang, H., Yang, B., and Sun, Q. (2021). Analysis of the Influencing Factors on the Anti-Aging Performance of a Hybrid-Modified Asphalt Mixture Using the Grey Relational Theory. Int. J. Pavement Eng. 22 (5), 597-612. doi:10.1080/10298436.2019.1630738

Khuman, A. S., Yang, Y., and John, R. (2019). The Quantification of Subjectivity: The R-Fuzzy Grey Analysis Framework. Expert Syst. Appl. 136, 201-216. doi:10.1016/j.eswa.2019.06.043

Li, H., and Wang, X. (2019). Analysis of Air Quality and Influencing Factors in Beijing-Tianjin-Hebei Region From 2013 to 2017. Adm. Tech. Environ. Monit. 31 (2), 21-25. doi:10.19501/j.cnki.1006-2009.20190313.012

Li, J., and Ye, S. (2020). Regional Policy Synergy and Haze Governance-Empirical Evidence From 281 Prefecture-Level Cities in China. Environ. Sci. Pollut. Res. 28 (9), 10763-10779. doi:10.1007/S11356-020-11251-8

Li, X., Zhang, Q., Zhang, Y., Zheng, B., Wang, K., Chen, Y., et al. (2015). Source Contributions of Urban PM2.5 in the Beijing-Tianjin-Hebei Region: Changes Between 2006 and 2013 and Relative Impacts of Emissions and Meteorology:Changes Between 2006 and 2013 and Relative Impacts of Emissions and Meteorology. Atmos. Environ. 123, 229-239. doi:10.1016/ j.atmosenv.2015.10.048

Liu, R., Liu, J., Zhang, Z., Borthwick, A. G. L., Cai, Y., Dong, L., et al. (2018). Risks of Airborne Pollution Accidents in a Major Conurbation: Case Study of Zhangjiakou, a Host City for the 2022 Winter Olympics. Stoch Environ. Res. Risk Assess. 32 (11), 3257-3272. doi:10.1007/s00477-0181590-5

Luo, X., Lu, L., Wang, Z., and Yang, L. (2019). Gray Correlation Analysis of Energy Consumption, Environmental Pollution, and Economic Growth in Subtropical Regions of China: Guangxi and Zhejiang as Examples. Trop. Conservation Sci. 12, 194008291984810. doi:10.1177/1940082919848101

Nan, G., and Sun, H. (2017). Analysis of Factors Affect-Ing $\mathrm{O}_{3}$ Concentration in Shaanxi Province Based on Grey Relational Model. Acta Scie-ntiae Circumstantiae. 37 (12), 4519-4527. doi:10.13671/j.hjkxxb.2017.0313

Ni, H. (2013). Assessment of Air Quality and Analysis of Influencing Factors in Wuhan Based on Grey Model. Wuhan: Huazhong University of Science and Technology.

\section{FUNDING}

The relevant researches are supported by the National Natural Science Foundation of China (71871084,U20A20316), Young talent support scheme of Hebei Province (360-0803-YBN7U2C), the Excellent Young Scientist Foundation of Hebei Education Department (SLRC2019001) and the Natural Science Foundation of Hebei Province (E2020402074).

\section{ACKNOWLEDGMENTS}

The authors appreciate the valuable suggestions and objective comments made by the reviewers.

Qazi, T. F., Shaukat, M. Z., Niazi, A. A. K., and Basit, A. (2021). Evaluating the Immediate Response of Country-Wide Health Systems to the Covid-19 Pandemic: Applying the Gray Incidence Analysis Model. Front. Public Health. 9, 9. doi:10.3389/FPUBH.2021.635121

Tian, Y., Jiang, Y., Liu, Q., Xu, D., Zhao, S., He, L., et al. (2019). Temporal and Spatial Trends in Air Quality in Beijing. Landscape Urban Plann. 185, 35-43. doi:10.1016/j.landurbplan.2019.01.006

Wang, C., Wang, G., and Wu, L. (2019). Study on Influencing Factors of Air Quality in Ha-Ndan Based on Grey Relational Analysis Fr-Om the Perspective of Economic and Soci-Al Indicators. Maths. Pract. Theor. 49 (17), 151-155.

Wang, J., Qian, W., Du, J., and Liu, Y. (2020). Effective Allocation of Resources in Water Pollution Treatment Alternatives: a Multi-Stage gray Group DecisionMaking Method Based on Hesitant Fuzzy Linguistic Term Sets. Environ. Sci. Pollut. Res. 27 (3), 3173-3186. doi:10.1007/s11356-019-07265-6

Wang, L., and Tian, D. (2019). Analysis of Influencing Factors of Air Quality in Yichang Based on Grey Relational Analysis Method. Energ. Environ. Prot. 33 (5), 60-64.

Wang, O., and He, B. (2018). Study on the Relationship Between PM 2.5 and Six Elements of Ambient Air Quality in Urumqi Based on Grey Relational Grade. J. Arid Land Resour. Environ. 32 (6), 176-181. doi:10.13448/ j.cnki.jalre.2018.191

Wang, X. (2020). Analysis of Influencing Factors of Smog in Zhengzhou Based on Improve-D Grey Relational Grade. Maths. Pr-actice Theor. 50 (01), 143-153.

Wang, Y., Shi, M., Lv, Z., Liu, H., and He, K. (2021). Local and Regional Contributions to PM2.5 in the Beijing 2022 Winter Olympics Infrastructure Areas During Haze Episodes. Front. Environ. Sci. Eng. 15 (6), 140. doi:10.1007/ S11783-021-1434-2

Wu, H., and Qu, Z. (2020). Gray Clustering Model Based on the Degree of Dynamic Weighted Incidence for Panel Data and its Application. Grey Systems: Theory and Application. 10 (4), 413-423. doi:10.1108/GS-09-2019-0040

Wu, L., Guo, X., and Chen, Y. (2021). Grey Relational Entropy Calculation and Fractional Prediction of Water and Economy in the Beijing-Tianjin-Hebei Region. J. Maths. 2021, 1-16. doi:10.1155/2021/4418260

Xiao, Q., Shan, M., Gao, M., Xiao, X., and Guo, H. (2021). Evalua-tion of the Coordination Between China's Technology and Economy Using a Grey MulTivariate Coupling Model. Technol. an-d Econ. Develop. Economy. 27 (1), 24-44. doi:10.3846/tede.2020.13742

Xiao, Q., Shan, M., Xiao, X., and Rao, C. (2020). Evaluation Model of Industrial Operation Quality Under Multi-Source Heterogeneous Data Information. Int. J. Fuzzy Syst. 22 (2), 522-547. doi:10.1007/s40815-019-00776-x

Xiao, X. (1997). Theoretical Research and Comments on Grey Relational Metric Model. Syst. Engineering-Theory Pract. 6 (8), 76-81. doi:10.3321/j.issn:1000 6788.1997.08.014

Yan, D., Lei, Y., Shi, Y., Zhu, Q., Li, L., and Zhang, Z. (2018). Evolution of the Spatiotemporal Pattern of PM2.5 Concentrations in China - A Case Study From the Beijing-Tianjin-Hebei Region. Atmos. Environ. 183, 225-233. doi:10.1016/ j.atmosenv.2018.03.041

Zhan, S., Kuang, Y., and Ruan, Z. (2018). Analysis of Influencing Factors of Air Quality in Gua-Ngdong-Hong Kong-Macao Greater Bay Ar-Ea Based on Grey 
Correlation Degree. Jo-urnal Tsinghua University (Science Technology). 58 (8), 761-767. doi:10.16511/j.cnki.qhdxxb.2018.26.031

Zhang, X., Shi, M., Pang, R., and Xiang, N. (2018). Correlating PM2.5 Concentrations With Air Pollutant Emissions: A Longitudinal Study of the Beijing-Tianjin-Hebei Region:A Longitudinal Study of the Beijing-TianjinHebei Region. J. Clean. Prod. 179, 103-113. doi:10.1016/j.jclepro.2018.01.072

Zhu, L., Zhao, C., and Dai, J. (2021). Prediction of Compressive Strength of Recycled Aggregate concrete Based on Gray Correlation Analysis. Construction Building Mater. 273, 121750. doi:10.1016/J.CONBUILDMAT.2020.121750

Conflict of Interest: The authors declare that the research was conducted in the absence of any commercial or financial relationships that could be construed as a potential conflict of interest.
Publisher's Note: All claims expressed in this article are solely those of the authors and do not necessarily represent those of their affiliated organizations, or those of the publisher, the editors, and the reviewers. Any product that may be evaluated in this article, or claim that may be made by its manufacturer, is not guaranteed or endorsed by the publisher.

Copyright (c) 2021 Wang, Chen, Xie and Wu. This is an open-access article distributed under the terms of the Creative Commons Attribution License (CC $B Y$ ). The use, distribution or reproduction in other forums is permitted, provided the original author(s) and the copyright owner(s) are credited and that the original publication in this journal is cited, in accordance with accepted academic practice. No use, distribution or reproduction is permitted which does not comply with these terms. 